ISSN 0103-9954

\title{
ENRAIZAMENTO DE MINIESTACAS E PRODUTIVIDADE DE MINICEPAS DE CEDRO AUSTRALIANO MANEJADAS EM CANALETÕES E TUBETES
}

\section{ROOTING OF MINICUTTINGS AND MANAGED PRODUCTIVITY OF AUSTRALIAN CEDAR MINISTRAINS GROWN IN LIFTED SEEDBEDS AND TUBES}

\author{
Mírian Peixoto Soares da Silva ${ }^{1}$ Deborah Guerra Barroso ${ }^{2}$ Juliana Sobreira de Souza ${ }^{3}$ \\ Daniele de Alvarenga Ferreira ${ }^{4}$ José Geraldo de Araújo Carneiro ${ }^{5}$
}

\begin{abstract}
RESUMO
Os povoamentos florestais plantados buscam atender à demanda crescente por madeira, principalmente, para as indústrias de serraria e de laminação, que utilizavam madeira exclusivamente de matas nativas. O cedro australiano (Toona ciliata), pertencente à família Meliaceae, é uma das espécies de interesse desse setor. Pela necessidade cada vez maior por mudas de alta qualidade, estudos sobre propagação de cedro australiano têm sido realizados nos últimos anos, principalmente envolvendo o uso da miniestaquia. Os objetivos deste trabalho foram avaliar o enraizamento e a capacidade produtiva das minicepas de cedro australiano, manejadas em sistemas de canaletões e em tubetes de $180 \mathrm{~cm}^{3}$. Assim, estabeleceram-se dois minijardins de minicepas formadas a partir de mudas recepadas, produzidas por sementes. Nestes dois sistemas, foram realizadas coletas sucessivas de brotações para confecção de miniestacas, que permaneceram por 30 dias no setor de enraizamento, em câmara com nebulização intermitente. Após este período, foram avaliadas as características do enraizamento das mudas originadas nos dois sistemas de minijardins testados, que foram conduzidos por sete meses e, durante este período, foram realizadas seis coletas no minijardim de canaletão e quatro, no de tubetes. As minicepas dos dois sistemas apresentam $100 \%$ de sobrevivência. Ao final do período observou-se tendência no aumento do número médio de miniestacas em ambos os sistemas. As minicepas do sistema de minijardim em canaletão são mais produtivas que as do sistema conduzido em tubetes. As mudas originadas de miniestacas do sistema de tubetes apresentam maior número e comprimento de raízes adventícias na expedição do setor de enraizamento.
\end{abstract}

Palavras-chave: Toona ciliata; miniestaquia; minijardim clonal.

\section{ABSTRACT}

The planted forest stands aim to supply the growing demand for wood, especially for the sawing and veneer industries, that exclusively used wood from native forests. The Australian cedar (Toona ciliata) belongs to the family Meliaceae, is the species of interest for this sector. Studies with the Australian cedar propagation have carried out in latest years, mainly involving the use of mini-cuttings due to the need for high quality cuttings. The objectives of this paper were to evaluate the rooting and the productive capacity of Australian

1. Engenheira Agrônoma, Msc., Doutoranda do Programa de Pós-graduação em Produção Vegetal, Laboratório de Fitotecnia (LFIT), Centro de Ciências e Tecnologias Agropecuárias, Universidade Estadual do Norte Fluminense Darcy Ribeiro, Av. Alberto Lamego, 2000, Parque Califórnia, CEP 28013-602, Campos dos Goytacazes (RJ). mirianpsoares@gmail.com

2. Engenheira Agrônoma, Dr ${ }^{\mathrm{a}}$, Professora de Silvicultura, Laboratório de Fitotecnia (LFIT), Centro de Ciências e Tecnologias Agropecuárias, Universidade Estadual do Norte Fluminense Darcy Ribeiro, Av. Alberto Lamego, 2000, Parque Califórnia, CEP 28013-602, Campos dos Goytacazes (RJ). deborah@uenf.br

3. Licenciada em Biologia, Msc., Doutoranda do Programa de Pós-graduação em Ecologia e Recursos Naturais, Laboratório de Ciências Ambientais, Centro de Biociências e Biotecnologia, Universidade Estadual do Norte Fluminense Darcy Ribeiro, Av. Alberto Lamego, 2000, Parque Califórnia, CEP 28013-602, Campos dos Goytacazes (RJ).julianauenf@gmail.com

4. Engenheira Agrônoma, Msc., Viveirista, CEP 28360-000, Bom Jesus do Itabapoana (RJ). ferreira.da@gmail.com

5. Engenheiro Florestal, PhD., Pesquisador Associado, Laboratório de Fitotecnia (LFIT), Centro de Ciências e Tecnologias Agropecuárias, Universidade Estadual do Norte Fluminense Darcy Ribeiro, Av. Alberto Lamego, 2000, Parque Califórnia, CEP 28013-602, Campos dos Goytacazes (RJ). carneiro@uenf.br

Recebido para publicação em 27/05/2010 e aceito em 08/08/2011 
cedar mini-strains, managed in lifted seedbeds and $180 \mathrm{~cm}^{3}$ plastic tubes systems. So, two mini-clone gardens were set up. The mini-strains of both gardens were grown from cut-off seedlings originated from seeds. Successive collections of sprouts were carried out to get the mini-cuttings. Afterwards, they remained in the rooting area under intermittent mist. Thirty days later the rooting characteristics of the cuttings originated from both mini-gardens were evaluated. The period of permanence of the cuttings in the gardens was seven-month long. During this period, six collections from the lifted seedbed and four from the plastic tubes were carried out. The mini-strains in the two systems showed $100 \%$ of survival rate. At the end of this seven-month period, an increasing tendency of the average number of mini-cutting was found out in both systems. Those from the lifted seedbed showed more productivity than those ones from the tubes. The plants from the mini-cuttings of the tube showed higher number and length of adventitious roots at the end rooting stage.

Keywords: Toona ciliata; mini-cuttings; mini-clone garden.

\section{INTRODUÇÃO}

Os povoamentos florestais plantados representam uma alternativa para atender à demanda crescente por madeira, principalmente, para o setor de serraria e de laminação que até então sobreviviam exclusivamente de matas nativas (PINHEIRO et al., 2006). Com isso, a procura por espécies que apresentem características de interesse econômico como ciclo curto, boa produtividade e qualidade da madeira, bem como diversificação de usos industriais têm aumentado (SOUZA JUNIOR, 2007).

O cedro australiano (Toona ciliata), pertencente à família Meliaceae, é uma dessas espécies. Originário das regiões tropicais da Austrália, adaptou-se bem ao Brasil, principalmente no Sul da Bahia e em toda região Sudeste (PINHEIRO et al., 2006), e vem se destacando no mercado mundial, onde sua madeira tem atingido altas cotações.

Para implantação de povoamentos florestais é preciso atentar para a qualidade das mudas utilizadas, que determinará o percentual de sobrevivência e o desenvolvimento pós-plantio. A maioria das mudas disponíveis no mercado é formada a partir de sementes (LORENZI et al., 2003; PINHEIRO et al., 2003), que resultam, nesta espécie, na formação de plantios heterogêneos, característica indesejável em plantios comerciais.

Neste caso, a propagação vegetativa constitui uma opção viável para produção de mudas uniformes, permitindo ainda rápida seleção e multiplicação de indivíduos adultos com características desejáveis, o que poderá refletir diretamente na qualidade e quantidade da madeira produzida. A técnica da miniestaquia tem sido utilizada por diferentes empresas para a multiplicação de clones de espécies florestais comerciais.

O estabelecimento de minijardins permite uma série de vantagens como: melhor controle nutricional e fitossanitário (ALFENAS et al., 2009), redução de custos com transporte de pessoal e material a ser propagado (HIGASHI et al., 2000a), maior produção por área, em menor tempo, quando comparado à estaquia convencional (ASSIS, 1997).

Alguns dos sistemas utilizados para condução de minicepas são os minijardins estabelecidos em tubetes de polipropileno e em canaletões de fibrocimento (HIGASHI et al., 2000a; SILVEIRA, 2001; HIGASHI et al., 2002; ALFENAS et al., 2009). A diferença entre esses dois sistemas não é apenas estrutural, mas também no manejo adotado. Nos canaletões a restrição radicular, as perdas de nutrientes e de água são menores, com relação aos tubetes. Com isso, com minijardins em tubetes a necessidade de maior frequência de irrigação e reposição de nutrientes, principalmente à base de nitrogênio, é necessária. Entretanto, em tubetes, o controle fitossanitário e nutricional pode ser realizado individualmente, minicepas fora do padrão de qualidade ou que apresentarem problemas fitossanitários podem ser substituídas, sem prejuízo na métrica do sistema.

Para garantir maior eficiência e uniformidade da produção de miniestacas, é recomendado que a coleta de brotações seja realizada de maneira seletiva e contínua, permitindo à minicepa bom estado vegetativo e sistema radicular ativo (TITON et al., 2003; ALFENAS et al., 2009). Higashi et al. (2000b) recomendaram que o intervalo entre uma coleta e outra seja entre 15-30 dias, podendo variar em função da estação do ano. De acordo com a espécie, a adoção de intervalos longos entre uma coleta e outra de miniestacas pode ser conveniente, pois desta forma, as minicepas sofrem 
menor estresse, aumentando a produtividade, além de reduzir custos com mão de obra (CUNHA et al., 2005). Souza et al. (2009), ao coletarem miniestacas de cedro australiano em sistema de tubetes, concluíram que, quanto maior o intervalo entre as coletas e quanto maiores as brotações que originaram as miniestacas, maior a velocidade de crescimento das mudas clonais produzidas, devido ao acúmulo de reservas ocorrido no período entre coletas.

Essa variação no intervalo entre coletas é geralmente observada em sistemas de minijardins clonais e pode ocorrer de acordo com o tipo de minijardim, com as condições ambientais, como temperatura e intensidade luminosa, espécie em estudo e nutrição mineral (HIGASHI et al., 2002).

A miniestaquia foi testada com sucesso na produção de mudas clonais de cedro australiano, por Souza et al. (2009), que obtiveram bom enraizamento de miniestacas, sem a necessidade de aplicação de reguladores de crescimento. Ferreira (2009) também utilizou esta técnica para a produção de mudas clonais de cedro australiano para testar o enraizamento em miniestacas coletadas em diferentes posições nas brotações (apical, intermediária e basal) originadas em minijardim de canaletão e observou que todas as posições de coleta foram aptas à produção de mudas desta espécie. Entretanto, para o cedro australiano, ainda não existem relatos sobre a capacidade produtiva e o período de vida útil das minicepas após serem submetidas a sucessivas coletas.

Neste contexto, os objetivos deste trabalho foram avaliar a sobrevivência e a capacidade produtiva das minicepas de cedro australiano (Toona ciliata), produzidas por sementes, e manejadas em sistemas de canaletões e em tubetes, ao longo de coletas sucessivas e o enraizamento de miniestacas coletadas nesses dois sistemas.

\section{MATERIAL E MÉTODO}

Este experimento foi realizado na Unidade de Apoio à Pesquisa (UAP), localizada na Universidade Estadual do Norte Fluminense Darcy Ribeiro, no município de Campos dos Goytacazes, RJ, latitude $21^{\circ} 19^{\prime} 23^{\prime \prime} \mathrm{S}$ e longitude $41^{\circ} 19^{\prime} 41^{\prime \prime} \mathrm{W}$. De acordo com a classificação de Köppen, o clima da região é do tipo Aw, tropical quente e úmido, com período de estiagem no inverno e chuvoso no verão.

Para implantação dos minijardins clonais, as sementes de cedro australiano (Toona ciliata $\mathrm{M}$.
Roem. var. australis (F. Muell.) Bahadur) foram adquiridas na firma Caiçara Comércio de Sementes Ltda., em Brejo Alegre, SP, provenientes de Área de Produção de Sementes (APS), localizada em Venda Nova do Imigrante, ES. Estas sementes foram acondicionadas em geladeira até a semeadura.

O substrato usado para produção das mudas foi uma mistura de Plantmax ${ }^{\circledR}$ florestal (Eucatex Agro), fibra de coco Golden Mix ${ }^{\circledR}$ mista (Amafibra) e torta de filtro, na proporção 2:1:1, respectivamente. A fibra de coco foi desfibrada e umedecida, conforme especificação do fabricante, e permaneceu em repouso por $24 \mathrm{~h}$. Para enriquecimento desta mistura, foram adicionados $2,2 \mathrm{Kg} \mathrm{m}^{-3}$ de ureia revestida e $1,5 \mathrm{Kg} \mathrm{m}^{-3}$ de superfosfato simples, conforme metodologia utilizada por Azevedo et al. (2009). Após o preparo da mistura, foi realizado o enchimento dos tubetes plásticos com capacidade de $180 \mathrm{~cm}^{3}$, que foram colocados em casa de vegetação coberta com plástico (filme agrícola 150 $\mu \mathrm{m})$ e sombrite $30 \%$. A semeadura foi realizada em 11 de fevereiro de 2009. Após 30 dias, foi realizado o desbaste com auxílio de uma espátula, sendo mantida a planta mais vigorosa e mais centralizada por tubete. Estas mudas foram conduzidas até uma altura variando de 14 a $22 \mathrm{~cm}$ de altura, sendo as mesmas irrigadas duas vezes ao dia com o auxílio de mangueira.

Para montagem do minijardim em canaletão foram utilizados dois canaletões de fibrocimento de $3,0 \mathrm{~m}$ de comprimento, $0,9 \mathrm{~m}$ de largura e $0,3 \mathrm{~m}$ de profundidade. Os canaletões tiveram as extremidades vedadas com tábuas de madeira. Para a drenagem da água de irrigação, o fundo foi perfurado a cada $30 \mathrm{~cm}$ e forrado com filme agrícola de $150 \mu \mathrm{m}$ em toda sua extensão, sobre o qual foram adicionados $5 \mathrm{~cm}$ de brita $\mathrm{n}^{\circ} 1$. Sobre a brita, foram colocados sombrite $70 \%$ e $10 \mathrm{~cm}$ de areia lavada, e sobre esta, $15 \mathrm{~cm}$ da mesma mistura e proporção dos substratos utilizados na produção das mudas. Para a montagem do minijardim em tubetes foram utilizadas oito bandejas com capacidade para 54 tubetes de $180 \mathrm{~cm}^{3}$, que foram dispostas em uma bancada suspensa de madeira. Os dois sistemas de minijardins foram manejados sob estrutura de casa de vegetação com cobertura plástica (filme agrícola $150 \mu \mathrm{m})$ e sombrite $30 \%$.

Para a implantação do banco de miniestacas (minijardim clonal seminal), aos 62 dias após semeadura, foram utilizadas 183 mudas para cada sistema. Sendo que nos canaletões, o transplantio obedeceu ao espaçamento de $0,15 \times 0,15 \mathrm{~m}$ e para os 
tubetes, a transferência das mudas para as bandejas obedeceu a uma densidade de 27 mudas por bandeja $(0,4 \times 0,6 \mathrm{~m})$.

Aos 96 dias após semeadura, foi realizada uma medição de altura e diâmetro iniciais das mudas que deram origem às minicepas dos dois sistemas de minijardins. Todas as minicepas foram identificadas individualmente, bem como as miniestacas provenientes de cada coleta, para posterior correlação com os dados de altura e diâmetro iniciais. Neste mesmo dia foi realizada a decepa, onde a parte aérea das mudas foi retirada a uma altura de $8 \mathrm{~cm}$ da base, formando, assim, as minicepas responsáveis pelo fornecimento de miniestacas. A partir deste momento, os dois sistemas passaram a ser monitorados a cada 15 dias, com relação ao diâmetro da minicepa, altura, número e diâmetro da brotação dominante. Este monitoramento foi utilizado para determinar as épocas de intervenção nos sistemas para a coleta de miniestacas.

Todas as posições de coleta (apical, intermediária e basal) das miniestacas nas brotações foram utilizadas. Este procedimento foi adotado, pois Ferreira (2009), ao trabalhar com cedro australiano nas mesmas condições deste experimento não observou diferença no crescimento pós-plantio, entre as mudas produzidas a partir de diferentes posições na brotação.

Ao atingirem o comprimento mínimo de $5 \mathrm{~cm}$, as brotações derivadas das minicepas dos dois sistemas de manejo foram colhidas com o auxílio de tesoura de poda, para a quantificação do número de miniestacas produzidas e preparo das mesmas, sendo mantidas uma ou duas folhas, conforme a posição da miniestaca na brotação, com dois pares de folíolos, reduzidos em $60 \%$ de sua área foliar em cada miniestaca. Após o preparo das miniestacas, parte foi utilizada para a produção de mudas e o restante apenas contabilizado e descartado. O estaqueamento, sem aplicação de reguladores de crescimento, ocorreu em tubetes, de $180 \mathrm{~cm}^{3}$, com substrato comercial para mudas florestais, acrescido de Osmocote ${ }^{\circledR}$ 14-14-14, da empresa Produquímica (com liberação estimada de 3 a 4 meses), na dose de $9 \mathrm{~g}$ por $\mathrm{Kg}$ de substrato (dose média de acordo com a recomendação do fabricante). Estas foram levadas para a câmara de nebulização (ambiente coberto com filme agrícola de $150 \mu \mathrm{m}$ e sombrite $30 \%$, com sistema de nebulização intermitente), sendo o turno de rega adotado para nebulizar a cada $15 \mathrm{~m}$ por $20 \mathrm{~s}$. As miniestacas permaneceram nessas condições por 30 dias para enraizamento e após este período, em cada ciclo, foi realizada a avaliação do experimento. Foram avaliadas as mudas produzidas nos cinco primeiros ciclos. Em função das condições de temperatura elevada ocorrida nos ciclos iniciados aos 149 e 177 dias após decepa, o turno de rega foi modificado para nebulizar por $24 \mathrm{~h}$ a cada $15 \mathrm{~m}$ durante $40 \mathrm{~s}$.

Foram realizadas seis coletas de miniestacas no sistema em canaletão e quatro no sistema em tubetes, em intervalos variáveis conforme o crescimento e vigor das brotações. No canaletão, as duas primeiras coletas foram realizadas aos $50 \mathrm{e}$ 86 dias após a decepa; as demais coincidiram com o início das coletas no sistema de tubete, aos 115 , 149, 177, 212 dias após a decepa, num intervalo de aproximadamente 30 dias. Cada coleta realizada foi denominada ciclo de produção.

Aos 79 dias após a decepa, sendo observados sintomas visuais de deficiência nutricional nas minicepas pertencentes ao minijardim em tubetes, iniciou-se a aplicação de N, utilizando-se solução de $\left(\mathrm{NH}_{4}\right)_{2} \mathrm{SO}_{4}\left(50 \mathrm{mM} \mathrm{L}^{-1}\right)$, com aplicação de $5 \mathrm{~mL}$ por planta, semanalmente. Esta aplicação foi repetida até o final do experimento.

Ao serem expedidas da casa de nebulização, três mudas de cada repetição foram coletadas para avaliação quanto à massa seca da parte aérea (MSPA), número (NR), comprimento de raízes adventícias (CR) e massa seca de raiz (MSR). Para essas avaliações, as mudas foram cortadas à altura do colo; o número de raízes, contado; e o comprimento das raízes adventícias, medido com o auxílio de régua. As partes foram colocadas em sacos de papel e secas em estufa de circulação forçada a $70{ }^{\circ} \mathrm{C}$, por $72 \mathrm{~h}$, para pesagem.

A porcentagem de sobrevivência das minicepas foi calculada após a realização de seis coletas de miniestacas no sistema em canaletão e quatro coletas para o sistema em tubetes.

Para a avaliação do enraizamento das miniestacas produzidas nos dois sistemas, foram utilizadas 20 repetições e o número de mudas por parcela variou conforme disponibilidade de miniestacas em cada coleta, sendo as mesmas dispostas em delineamento inteiramente casualizado. Para as miniestacas originadas nos canaletões, as parcelas foram compostas por 12 mudas. Para as miniestacas originadas pelo minijardim de tubetes, as parcelas foram constituídas por 6, 7 e 9 mudas, referente aos ciclos de produção aos 115, 149 e 177 dias após a decepa, respectivamente. 
Os dados foram submetidos à análise de variância e as diferenças detectadas, comparadas pelo teste de Tukey, ao nível de $5 \%$ de probabilidade de erro.

\section{RESULTADOS E DISCUSSÃO}

A sobrevivência das minicepas de cedro australiano foi de $100 \%$ para os dois sistemas, durante sete meses de manejo, com seis coletas nas minicepas dos canaletões e quatro coletas nas dos tubetes. Este resultado está de acordo com vários trabalhos que testaram a sobrevivência de minicepas submetidas a coletas sucessivas, em diferentes espécies. Xavier et al. (2003), para Cedrella fissilis em minijardim de tubetes, obtiveram $100 \%$ de sobrevivência após quatro coletas sucessivas. Cunha et al. (2005), para minicepas de Eucalyptus benthamii, em minijardim de canaletão (leito de areia) e tubetes, observaram, após cinco coletas sucessivas, 88 e $100 \%$ de sobrevivência, respectivamente. Souza Junior (2007), Wendling et al. (2007) e Souza et al. (2009), também obtiveram altos valores de sobrevivência, acima de $95 \%$, em minicepas de Grevillea robusta, após 15 coletas em canaletão e tubete, Ilex paraguariensis (erva-mate), após 11 coletas em canaletão e Toona ciliata, após 3 coletas em tubetes, respectivamente.

$\mathrm{O}$ manejo adequado e a nutrição são muito importantes para a manutenção e vigor da minicepa, sendo um dos principais fatores que afetam o fornecimento de propágulos (HARTMANN et al., 2002).

No minijardim em canaletão houve maior número de coletas de miniestacas em relação aos tubetes, 6 e 4, respectivamente, e, quando as épocas de coleta coincidiram, o minijardim em canaletão produziu uma média de 3,5 miniestacas por minicepa, quando comparado ao outro sistema, 1,24 miniestacas por minicepa (Tabela 1). De forma geral, as minicepas do sistema de canaletão permitiram maior produção de miniestacas, com valores médios de 18,42 miniestacas por minicepa no período de sete meses, enquanto as minicepas dos tubetes produziram 4,94, no mesmo período, o que corresponde a aproximadamente $270 \%$ a mais que a produção das minicepas do minijardim em tubetes. Entretanto, é preciso considerar que o minijardim em tubetes ocupa uma área quatro vezes menor quando comparada ao minijardim em canaletão, o que reduz a diferença de produtividade entre os sistemas por área de viveiro.

O mesmo comportamento foi observado por Cunha et al. (2005), com média de 8,1 miniestacas por minicepa em sistema de canaletão, em comparação a 4,1 do sistema de tubetes em coletas que variaram entre 25 e 30 dias para Eucalyptus benthamii; por Souza Junior (2007), com Grevillea robusta, com a qual obteve média de produção de três miniestacas por minicepa, em

TABELA 1: Número médio de miniestacas por minicepa de cedro australiano (Toona ciliata) produzidas nos sistemas de minijardins de canaletão e tubetes.

TABLE 1: Mean number of mini-cuttings for Australian cedar (Toona ciliata) mini-stumps, produced in suspended seedbed and tube mini-garden systems.

\begin{tabular}{ccc}
\hline \multirow{2}{*}{ Ciclo de produção } & \multicolumn{2}{c}{ Número Médio de miniestacas/minicepa } \\
\cline { 2 - 3 } & Canaletão & Tubetes \\
\hline $1\left(50^{\mathrm{A}}\right)$ jul/09 & $2,77 \mathrm{C}$ & ------ \\
$2\left(86^{\mathrm{A}}\right)$ ago/09 & $1,65 \mathrm{D}$ & ------ \\
$3\left(115^{\mathrm{A}}\right)$ set/09 & $2,06 \mathrm{D}$ & $0,68 \mathrm{D}$ \\
$4\left(149^{\mathrm{A}}\right)$ out $/ 09$ & $3,34 \mathrm{~B}$ & $1,35 \mathrm{~B}$ \\
$5\left(177^{\mathrm{A}}\right)$ nov $/ 09$ & $2,95 \mathrm{BC}$ & $1,01 \mathrm{C}$ \\
$6\left(212^{\mathrm{A}}\right)$ dez/09 & $5,65 \mathrm{~A}$ & $1,90 \mathrm{~A}$ \\
\hline $\mathrm{CV}(\%)$ & 49,07 & 46,45 \\
\hline Média total de miniestacas/ & $18,42 \mathrm{a}$ & $4,94 \mathrm{~b}$ \\
minicepa $^{\mathrm{B}}$ & &
\end{tabular}

Em que: ${ }^{\mathrm{A}}=$ dias após decepa; Médias seguidas da mesma letra maiúscula na coluna e minúscula na linha não diferem entre si pelo teste de Tukey ao nível de $5 \%$ de probabilidade de erro. ${ }^{\mathrm{B}}=$ Médias diferem pelo $\mathrm{IC}_{95} \%$. 
15 coletas, no sistema de canaletão, com intervalo de 20 dias entre coletas e de 1,7 no sistema de tubetes, em intervalo de 25 dias e por Cunha et al. (2008) que, ao trabalharem com Erythrina falcata (corticeira-do-mato), obtiveram uma produtividade média quinzenal de 2,9 miniestacas por minicepa por coleta para o canaletão (total de oito coletas) e mensal de 1,3 em tubetes (total de quatro coletas). Segundo Assis e Mafia (2007), esta diferença pode ser explicada, principalmente, pelo aumento da área e volume de substrato disponível para exploração pelo sistema radicular da minicepa, e consequente disponibilidade nutricional.

Ferreira (2009), ao avaliar a produção de miniestacas de cedro australiano conduzidas em sistema de canaletão, obteve um total médio de 3,6 miniestacas por minicepa em sete coletas realizadas, no intervalo de 15 dias. A autora observou que o cedro australiano tem como característica, após a decepa, a manutenção da dominância de uma das brotações, o que tende a ser reduzido ao longo do tempo. Essa característica também foi observada por Souza et al. (2009), com a mesma espécie, e no presente estudo.

A produção média de miniestacas foi alternada ao longo das coletas realizadas, estando de acordo com resultados encontrados na literatura por Titon et al. (2003), Xavier et al. (2003) e Souza Junior (2007) ao trabalharem com Eucalyptus grandis, Cedrella fissilis e Grevillea robusta, respectivamente. Segundo estes autores, ao usarem a técnica de miniestaquia para as espécies estudadas, períodos de maior produção de brotações foram alternados por períodos de menor produtividade. Esse comportamento pode estar relacionado ao vigor fisiológico das minicepas (HIGASHI et al., 2002). Além disso, o aumento da produção de miniestacas registrado no terceiro ciclo de produção do minijardim em canaletão, com relação aos anteriores, pode estar associado à elevação da temperatura a partir deste período.

Wendling et al. (2003), ao estudarem a influência da miniestaquia seriada no vigor de minicepas de quatro clones de Eucalyptus grandis, observaram comportamento variável em função do clone, sendo que a produção oscilou de 2,0 a 9,7 miniestacas por minicepa, porém, sem apresentar uma tendência clara. Os autores sugeriram que esse comportamento pode estar associado à necessidade de adaptação inicial das minicepas ao sistema utilizado (hidroponia), bem como, à quebra de dominância apical após a decepa e que, após algumas coletas, as gemas dormentes tornaram-se reativas, resultando em maior estímulo ao crescimento e melhor ajuste ao manejo realizado.

Em estudo realizado por Brondani (2008), testando a produção de miniestacas em três clones de Eucalyptus benthamii x Eucalyptus dunnii, nas quatro estações do ano, foram observados os maiores índices de produção de miniestacas na primavera e no verão. A produção e o enraizamento de miniestacas variaram conforme o clone estudado e se mostraram muito sensíveis ao efeito da sazonalidade. Cunha et al. (2009) também citaram que as condições meteorológicas condicionam significativamente a produção de miniestacas por minicepa. Os autores observaram que o aumento da temperatura no leito de cultivo, ocasionado pela época do ano, favoreceu positivamente a produção de miniestacas de eucalipto, independente do tipo de minijardim clonal testado (leito de areia ou tubete).

$\mathrm{Na}$ Tabela 2 encontram-se as correlações entre o número total de miniestacas produzidas por minicepa e altura e diâmetro iniciais das mudas seminais que deram origem a estas minicepas.

As baixas correlações obtidas para

TABELA 2: Correlações ${ }^{1}$ de Pearson entre o total de miniestacas por minicepa de cedro australiano (Toona ciliata) produzidas após seis coletas no minijardim de canaletão e quatro no sistema de tubetes e altura e diâmetro iniciais das mudas que formaram os minijardins.

TABLE 2: $\quad$ Pearson correlations ${ }^{1}$ between the all mini-cutting per Australian cedar (Toona ciliata) ministump, produced after six collections in suspended seedbed mini-garden and four in tube system, and initial height and diameter of seedlings that composed the mini-garden.

\begin{tabular}{ccc}
\hline & \multicolumn{2}{c}{ Total de miniestacas/minicepa } \\
\hline & Canaletão & Tubetes \\
\hline Altura inicial $(\mathrm{cm})$ & $-0,0855$ & 0,2235 \\
Diâmetro inicial $(\mathrm{mm})$ & 0,0320 & 0,0977 \\
\hline
\end{tabular}

Em que: ${ }^{1}=373$ observações; 
os dois sistemas demonstram que o total de miniestacas produzidas por minicepas ocorreu independentemente das características biométricas das mudas que originaram as minicepas. As diferenças encontradas na produção de miniestacas, entre os dois sistemas, ocorreram devido aos tipos de sistemas de minijardins utilizados.

Na saída do setor de enraizamento, aos 30 dias após o estaqueamento, ao avaliar as mudas clonais provenientes de miniestacas coletadas no sistema de canaletão quanto às variáveis massa seca da parte aérea (MSPA), número, comprimento e massa seca de raízes adventícias (MSR) (Tabela 3), pode-se verificar que não houve diferença entre as mudas do segundo, terceiro e quarto ciclos de produção. Entre o primeiro e o último ciclo, houve aumento do número de raízes adventícias, sem alteração do comprimento e da MSR. O comprimento das raízes adventícias foi menor no último ciclo com relação aos ciclos 3 e 4 . A MSR foi menor no último ciclo com relação ao quarto ciclo. A MSPA foi menor nas mudas do segundo e quinto ciclos, quando comparadas às mudas do primeiro ciclo.

De forma geral, o quinto ciclo apresentou as menores médias quando comparado aos demais, exceto no número de raízes adventícias, que foi maior em relação ao primeiro ciclo. $\mathrm{O}$ aumento no número de raízes e redução na massa sugerem incremento de raízes finas, responsáveis pela absorção de água e nutrientes, sendo um fator importante para o desenvolvimento das mudas (FREITAS, 2007).

Mudas que apresentam grande número de raízes finas podem superar condições de estresse ambiental a que estão sujeitas no pós-plantio (FREITAS et al., 2005), pois estas constituem um dos principais meios para acessar os recursos do solo, sendo o comprimento e número dessas raízes indicadores da capacidade de absorção de nutrientes (RYLTER, 1997).

Já para as mudas originadas de miniestacas do sistema de tubetes, não houve diferença no número de raízes e MSR, na expedição do setor de enraizamento (Tabela 4). Entretanto, também houve redução da MSPA das mudas no último ciclo avaliado e no comprimento das raízes, lembrando que houve apenas quatro coletas neste sistema, em função do crescimento mais lento das brotações e que as mudas foram produzidas apenas nas três primeiras coletas para avaliação do enraizamento.

No momento da expedição do setor de enraizamento, não houve interação entre os três ciclos coincidentes e os dois sistemas de minijardins estudados para MSPA, número de raízes adventícias, comprimento e MSR (Tabela 5). As menores médias foram encontradas nas mudas do quinto ciclo de produção, exceto o número de raízes, que se manteve igual nos diferentes ciclos para cada sistema. Isto provavelmente deve-se ao aumento da temperatura e da frequência de nebulização ocorrida neste período. Em função das condições climáticas, foi aumentado o turno de rega da nebulização. Essa variação pode ter ocasionado estresse aos propágulos, considerando a maior sensibilidade das miniestacas às condições ambientais nos primeiros dias após a entrada no setor de enraizamento.

TABELA 3: Dados biométricos de mudas de cedro australiano (Toona ciliata), produzidas por miniestacas provenientes de sistema de canaletão, na expedição do setor de enraizamento, 30 dias após o estaqueamento, em cinco ciclos de produção.

TABLE 3: Biometric data of Australian cedar (Toona ciliata), produced by mini-cuttings from suspended seedbed system, at the end rooting stage, 30 days after staking, in five production cycles.

\begin{tabular}{ccccc}
\hline Ciclo de produção & MSPA $(\mathrm{g})$ & $\mathrm{NR}$ & $\mathrm{CR}(\mathrm{cm})$ & MSR $(\mathrm{g})$ \\
\hline $1\left(50^{\mathrm{A}}\right)$ jul/09 & $0,2255 \mathrm{~A}$ & $11,20 \mathrm{~B}$ & $43,13 \mathrm{C}$ & $0,0300 \mathrm{AB}$ \\
$2\left(86^{\mathrm{A}}\right)$ ago/09 & $0,1714 \mathrm{~B}$ & $13,30 \mathrm{AB}$ & $68,20 \mathrm{AB}$ & $0,0298 \mathrm{AB}$ \\
$3\left(115^{\mathrm{A}}\right)$ set/09 & $0,1917 \mathrm{AB}$ & $15,38 \mathrm{~A}$ & $81,38 \mathrm{~A}$ & $0,0356 \mathrm{AB}$ \\
$4\left(149^{\mathrm{A}}\right)$ out$/ 09$ & $0,2042 \mathrm{AB}$ & $17,23 \mathrm{~A}$ & $77,53 \mathrm{~A}$ & $0,0374 \mathrm{~A}$ \\
$5\left(177^{\mathrm{A}}\right)$ nov/09 & $0,1711 \mathrm{~B}$ & $16,60 \mathrm{~A}$ & $58,81 \mathrm{BC}$ & $0,0252 \mathrm{~B}$ \\
\hline $\mathrm{CV}(\%)$ & 42,654 & 53,698 & 54,013 & 75,044 \\
\hline
\end{tabular}

Em que: ${ }^{\mathrm{A}}=$ dias após decepa; MSPA = Massa seca da parte aérea; NR = Número de raízes adventícias; $\mathrm{CR}=$ Comprimento de raízes adventícias; MSR = Massa seca de raízes adventícias; Médias seguidas da mesma letra, na coluna, não diferem entre si pelo teste de Tukey ao nível de $5 \%$ de probabilidade de erro 
TABELA 4: Dados biométricos de mudas de cedro australiano (Toona ciliata) produzidas por miniestacas provenientes de sistema de tubetes, na expedição do setor de enraizamento, 30 dias após o estaqueamento, em três ciclos de produção.

TABLE 4: Biometric data of Australian cedar (Toona ciliata), produced by mini-cuttings from tube system, at the end rooting stage, 30 days after staking, in three production cycles.

\begin{tabular}{ccccc}
\hline Ciclo de produção & MSPA $(\mathrm{g})$ & NR & CR $(\mathrm{cm})$ & MSR $(\mathrm{g})$ \\
\hline $3\left(115^{\mathrm{A}}\right)$ set/09 & $0,1986 \mathrm{~A}$ & $21,03 \mathrm{~A}$ & $97,9467 \mathrm{~A}$ & $0,0307 \mathrm{~A}$ \\
$4\left(149^{\mathrm{A}}\right)$ out $/ 09$ & $0,1995 \mathrm{~A}$ & $21,77 \mathrm{~A}$ & $87,0800 \mathrm{AB}$ & $0,0307 \mathrm{~A}$ \\
$5\left(177^{\mathrm{A}}\right)$ nov/09 & $0,1471 \mathrm{~B}$ & $18,60 \mathrm{~A}$ & $71,3177 \mathrm{~B}$ & $0,0254 \mathrm{~A}$ \\
\hline CV $(\%)$ & 30,317 & 41,325 & 45,443 & 52,940 \\
\hline
\end{tabular}

Em que: ${ }^{\mathrm{A}}=$ dias após decepa; MSPA = Massa seca da parte aérea; NR = Número de raízes adventícias; $\mathrm{CR}=$ Comprimento de raízes adventícias; MSR = Massa seca de raiz; Médias seguidas da mesma letra na coluna não diferem entre si pelo teste de Tukey ao nível de $5 \%$ de probabilidade de erro

TABELA 5: Dados biométricos de mudas de cedro australiano (Toona ciliata) produzidas por miniestacas considerando a interação entre os sistemas de canaletão e tubetes, na expedição do setor de enraizamento, 30 dias após o estaqueamento, nos três ciclos de produção coincidentes.

TABLE 5: Biometric data of Australian cedar (Toona ciliata), produced by mini-cuttings from suspended seedbed and tube systems, at the end rooting stage, 30 days after staking, in the three coincident production cycles.

\begin{tabular}{ccccccccc}
\hline \multirow{2}{*}{$\begin{array}{c}\text { Ciclo de } \\
\text { produção }\end{array}$} & \multicolumn{2}{c}{ MSPA $(\mathrm{g})$} & \multicolumn{2}{c}{ NR } & \multicolumn{2}{c}{$\mathrm{CR}(\mathrm{cm})$} & \multicolumn{2}{c}{ MSR $(\mathrm{g})$} \\
\cline { 2 - 9 } C & $\mathrm{T}$ & $\mathrm{C}$ & $\mathrm{T}$ & $\mathrm{C}$ & $\mathrm{T}$ & $\mathrm{C}$ & $\mathrm{T}$ \\
\hline (115 $)$ & $0,1917 \mathrm{~A}$ & $0,1986 \mathrm{~A}$ & $15,39 \mathrm{~A}$ & $21,04 \mathrm{~A}$ & $81,38 \mathrm{~A}$ & $97,95 \mathrm{~A}$ & $0,0356 \mathrm{~A}$ & $0,0307 \mathrm{~A}$ \\
$\left(149^{\mathrm{A}}\right)$ & $0,2042 \mathrm{~A}$ & $0,1995 \mathrm{~A}$ & $17,24 \mathrm{~A}$ & $21,76 \mathrm{~A}$ & $77,53 \mathrm{~A}$ & $87,08 \mathrm{~A}$ & $0,0374 \mathrm{~A}$ & $0,0321 \mathrm{~A}$ \\
$5\left(177^{\mathrm{A}}\right)$ & $0,1711 \mathrm{~B}$ & $0,1471 \mathrm{~B}$ & $16,61 \mathrm{~A}$ & $18,59 \mathrm{~A}$ & $58,81 \mathrm{~B}$ & $71,32 \mathrm{~B}$ & $0,0252 \mathrm{~B}$ & $0,0254 \mathrm{~B}$ \\
\hline Média & $0,189 \mathrm{a}$ & $0,1817 \mathrm{a}$ & $16,41 \mathrm{~b}$ & $20,46 \mathrm{a}$ & $71,57 \mathrm{~b}$ & $85,45 \mathrm{a}$ & $0,0327 \mathrm{a}$ & $0,0294 \mathrm{a}$ \\
\hline $\mathrm{CV}(\%)$ & \multicolumn{2}{c}{16,78} & \multicolumn{2}{c}{23,03} & \multicolumn{2}{c}{25,46} & \multicolumn{2}{c}{31,80} \\
\hline
\end{tabular}

Em que: ${ }^{\mathrm{A}}=$ dias após decepa; MSPA = Massa seca da parte aérea; NR = Número de raízes adventícias; $\mathrm{CR}=$ Comprimento de raízes adventícias; $\mathrm{MSR}=$ Massa seca de raiz; $\mathrm{C}=$ canaletão; $\mathrm{T}=$ tubete; Médias seguidas da mesma letra maiúscula na coluna e minúscula na linha não diferem entre si pelo teste de Tukey ao nível de $5 \%$ de probabilidade de erro para cada variável

Um dos problemas encontrados na maior parte dos sistemas de controle de irrigação é justamente aflutuação daumidaderelativadoar, poisa irrigação é normalmente programada para intervalos fixos, não acompanhando a evapotranspiração das folhas das estacas, desconsiderando a sazonalidade (BERTOLOTI e GONÇALVES, 1980).

Entre os dois sistemas de produção houve diferença apenas no número e comprimento total de raízes adventícias, que foi maior nas mudas provenientes de miniestacas das minicepas conduzidas em tubetes (Tabela 5).

Além das condições climáticas, o enraizamento das miniestacas está diretamente ligado ao teor de carboidratos armazenado na matriz. Quanto maior o nível de reservas e maior a relação carbono/nitrogênio maior será o favorecimento do enraizamento das estacas (PAIVA e GOMES, 1995). Entretanto, neste experimento, o sistema de tubetes foi o que menos produziu miniestacas e mesmo assim, o incremento em raízes nas mudas clonais produzidas neste sistema foi superior ao sistema de canaletão, que apresentou maior vigor de minicepa, com maior crescimento e acúmulo de reservas.

A partir de observações visuais, percebeuse que as miniestacas coletadas no canaletão talvez tenham necessitado de maior investimento de reservas para manter o turgor da parte aérea após o estaqueamento, nas novas condições, e isso pode ter resultado em menor investimento em raízes quando comparadas às miniestacas mais lignificadas coletadas no sistema de tubetes.

Conhecer os efeitos dos fatores que afetam a formação de raízes e suas consequências é de 
fundamental importância para produção de mudas via enraizamento adventício, sendo esta uma das principais etapas na propagação vegetativa (DE KLERK et al., 1999). Dentre estes fatores estão a umidade, a temperatura (tanto no substrato quanto na atmosfera) e a luminosidade, além de outros fatores como a composição química e física do substrato (HIGASHI et al., 2000a). É no setor de enraizamento que são registradas as maiores taxas de mortalidade de mudas, podendo atingir mais de $20 \%$ (ZANNI FILHO, 1997).

A temperatura possui função regulatória no metabolismo das plantas, afetando o enraizamento. A divisão celular é favorecida com o aumento da temperatura e, consequentemente, auxilia a formação de raízes. No entanto, temperatura muito alta, durante a fase de enraizamento, estimula o desenvolvimento de gemas laterais antes do aparecimento de raízes (HARTMANN et al., 2002).

As correlações entre altura e diâmetro iniciais das mudas seminais que deram origem às minicepas e às variáveis biométricas das mudas produzidas: MSPA, número, comprimento e MSR de raízes, após expedição do setor de enraizamento, foram muito baixas, conforme pode ser verificado nas Tabelas 6, 7 e 8. Essas baixas correlações demonstram que as características das mudas após 30 dias no setor de enraizamento são independentes das características iniciais de altura e diâmetro das mudas que formaram os minijardins.

Ao longo do tempo, entre as diferenças de manejo para os dois sistemas testados, destacase a necessidade de maior frequência de irrigação e de reposição de nitrogênio no minijardim em tubetes, o que requer um maior cuidado e maior necessidade de mão de obra, encarecendo os custos de produção. Este sistema implica em maiores perdas de recursos, com menor produtividade por planta, embora compensada pelo maior número de minicepas por área de produção. Diante disso, entre os sistemas de minijardins utilizados, o de canaletão mostrou-se mais favorável à produção de mudas por

TABELA 6: Correlações ${ }^{1}$ de Pearson entre características das mudas seminais de cedro australiano (Toona ciliata) antes da decepa e dados biométricos das mudas clonais produzidas por miniestacas provenientes do sistema de canaletão, na expedição do setor de enraizamento, 30 dias após estaqueamento.

TABLE 6: Pearson Correlations ${ }^{1}$ between characteristics of Australian cedar (Toona ciliata) seedlings, before topping, and biometric data of the mini-cuttings coming from suspended seedbed system, at the end rooting stage, 30 days after staking.

\begin{tabular}{ccccc}
\hline & \multicolumn{4}{c}{ Dados biométricos das mudas produzidas } \\
\cline { 2 - 5 } & MSPA $(\mathrm{g})$ & NR & CR $(\mathrm{cm})$ & MSR $(\mathrm{g})$ \\
\hline Altura inicial $(\mathrm{cm})$ & $-0,1013$ & 0,0597 & 0,1077 & 0,0313 \\
Diâmetro inicial $(\mathrm{mm})$ & 0,0289 & 0,0833 & 0,0167 & 0,0296 \\
\hline
\end{tabular}

Em que: $\mathrm{MSPA}=$ Massa seca da parte aérea; $\mathrm{NR}=$ Número de raízes adventícias; $\mathrm{CR}=$ Comprimento de raízes adventícias; MSR = Massa seca de raiz; $1=299$ observações.

TABELA 7: Correlações ${ }^{1}$ de Pearson entre características das mudas seminais de cedro australiano (Toona ciliata) antes da decepa e dados biométricos de mudas clonais produzidas por miniestacas provenientes do sistema de tubetes, na expedição do setor de enraizamento, 30 dias após estaqueamento.

TABLE 7: Pearson Correlations ${ }^{1}$ between characteristics of Australian cedar (Toona ciliata) seedlings before topping, and biometric data of the mini-cuttings coming from tube system, at the end rooting stage, 30 days after staking.

\begin{tabular}{ccccc}
\hline & \multicolumn{4}{c}{ Dados biométricos das mudas produzidas } \\
\cline { 2 - 5 } & MSPA $(\mathrm{g})$ & NR & CR $(\mathrm{cm})$ & MSR $(\mathrm{g})$ \\
\hline Altura inicial $(\mathrm{cm})$ & $-0,0676$ & $-0,1291$ & $-0,0665$ & $-0,0990$ \\
Diâmetro inicial $(\mathrm{mm})$ & 0,0836 & 0,0730 & 0,1637 & 0,1403 \\
\hline
\end{tabular}

Em que: $\mathrm{MSPA}=$ Massa seca da parte aérea; $\mathrm{NR}=$ Número de raízes adventícias; $\mathrm{CR}=$ Comprimento de raízes adventícias; MSR $=$ Massa seca de raiz; ${ }^{1}=90$ observações. 
TABELA 8: Correlações ${ }^{1}$ de Pearson entre características das mudas seminais de cedro australiano (Toona ciliata) antes da decepa e dados biométricos de mudas clonais produzidas por miniestacas provenientes dos sistemas de canaletão e tubetes, na expedição do setor de enraizamento, 30 dias após estaqueamento.

TABLE 8: Pearson Correlations ${ }^{1}$ between characteristics of Australian cedar (Toona ciliata) seedlings before topping, and biometric data of the mini-cuttings coming from suspended seedbed and tubes systems, at the end rooting stage, 30 days after staking.

\begin{tabular}{ccccc}
\hline & \multicolumn{4}{c}{ Dados biométricos das mudas produzidas } \\
\cline { 2 - 5 } & MSPA $(\mathrm{g})$ & $\mathrm{NR}$ & $\mathrm{CR}(\mathrm{cm})$ & $\mathrm{MSR}(\mathrm{g})$ \\
\hline Altura inicial $(\mathrm{cm})$ & $-0,0362$ & $-0,1553$ & $-0,0744$ & 0,0409 \\
Diâmetro inicial $(\mathrm{mm})$ & 0,0641 & $-0,1102$ & $-0,0997$ & 0,0568 \\
\hline
\end{tabular}

Em que: $\mathrm{MSPA}=$ Massa seca da parte aérea; $\mathrm{NR}=$ Número de raízes adventícias; $\mathrm{CR}=$ Comprimento de raízes adventícias; MSR = Massa seca de raiz; $1=389$ observações.

miniestaquia, no intervalo de tempo do experimento.

Devem ser realizados novos estudos testando as coletas sucessivas em minicepas de cedro australiano nos dois sistemas de manejo utilizados, por um período mínimo de um ano, visando avaliar o comportamento das minicepas nas diferentes estações do ano, bem como o período de esgotamento das mesmas.

\section{CONCLUSÕES}

As minicepas dos dois sistemas, canaletão e tubetes, apresentam $100 \%$ de sobrevivência.

Ao longo das coletas realizadas, não há queda de produtividade das minicepas.

As minicepas do minijardim em canaletão produzem $270 \%$ de miniestacas a mais do que as minicepas do minijardim em tubetes, no período de sete meses.

Ao longo das coletas sucessivas do sistema de canaletão há aumento no vigor das mudas na expedição do setor de enraizamento.

As mudas originadas de miniestacas do sistema de tubetes apresentam maior número e comprimento de raízes adventícias no final do período de enraizamento.

\section{REFERÊNCIAS BIBLIOGRÁFICAS}

ALFEnAS, A. C. et al. Clonagem e Doenças do Eucalipto. 2. ed. Viçosa: Universidade Federal de Viçosa, 2009. 500 p.

ASSIS, T. F. de.; MAFIA, R. G. Hibridação e clonagem. In: BORÉM, A. (Ed.). Biotecnologia florestal. Viçosa: Suprema Gráfica e Editora, 2007. p. 93-121.

ASSIS, T. F.Propagação vegetativa de Eucalyptus por microestaquia. In: IUFRO: CONFERENCE ON SILVICULTURE AND IMPROVEMENT OF EUCALYPT, 1997, Salvador. Anais... Colombo: EMBRAPA-CNPF, 1997, p. 300-304.

AZEVEDO, E. B. et al. Substratos fertilizados com uréia revestida e o crescimento e estado nutricional da muda de citros. Acta Scientiarum. Agronomy, Maringá, v. 31, n. 1, p. 129-137, 2009.

BERTOLOTI, G., GONÇALVES, A. N. Enraizamentode estacas: especificações técnicas para construção do módulo de enraizamento. Circular Técnica IPEF, n. 94, p. 1-7, 1980.

BRONDANI, G. E. Miniestaquia e micropropagação de Eucalyptus benthamii Maiden \& Cambage x Eucalyptus dunnii Maiden. 2008. 118 f. Dissertação (Mestrado em Engenharia Florestal) -Universidade Federal do Paraná, Curitiba-PR, 2008.

CUNHA, A. C. M. C. M. da. et al. Miniestaquia em sistema de hidroponia e em tubetes de corticeira-domato. Ciência Florestal, Santa Maria, v. 18, n. 1, p. 85-92, 2008.

CUNHA, A. C. M. C. M. da. et al. Produtividade e Sobrevivência de Minicepas de Eucalyptus benthamii Maiden et Cambage em Sistema de Hidroponia e em Tubetes. Ciência Florestal, Santa Maria, v. 15, n. 3, p. 307-310, 2005.

CUNHA, A. C. M. C. M. da. et al. Relações entre variáveis climáticas com produção e enraizamento de miniestacas de eucalipto. Revista Árvore, Viçosa, v. 33, n. 2, p. 195-203, 2009.

FERREIRA, D. de A. Produtividade das minicepas de cedro australiano em minijardim multiclonal e influência da posição das miniestacas na qualidade das mudas. 2009. 55f. Dissertação (Mestrado em Produção Vegetal)- Universidade Estadual do Norte Fluminense Darcy Ribeiro 
Campos dos Goytacazes, 2009.

FREITAS, T. A. S. de. et al. Desempenho Radicular de Mudas de Eucalipto Produzidas em Diferentes Recipientes e Substratos. Revista Árvore, Viçosa, v. 29, n. 6, p. 853-861, 2005.

FREITAS, T. A. S. de. Produção de mudas de eucalipto em recipiente aberto e fechado. 2007. 91f. Tese (Doutorado em Produção Vegetal)Universidade Estadual do Norte Fluminense Darcy Ribeiro, Campos dos Goytacazes, 2007.

HARTMANN, H. T. et al. Plant propagation: principles and practices. 7 th ed. New Jersey: Prentice - Hall, 2002. 880 p.

HIGASHI, E. N. et al. A evolução do jardim clonal na produção de mudas. IPEF notícias, v. $24, \mathrm{n}$. 148, p. 4-6. 2000 b.

HIGASHI, E. N. et al. Nutrição e Adubação em minijardim clonal hidropônico de Eucalyptus.

Circular Técnica IPEF, Piracicaba-SP, n. 194, 22 p. 2002.

HIGASHI, E. N. et al. Propagação vegetativa do Eucalyptus: princípios básicos e sua evolução no Brasil. Circular Técnica IPEF, Piracicaba, SP, n. 192, 11 p. 2000a.

LORENZI, H. et al. Árvores Exóticas no Brasil: madeireiras, ornamentais e aromáticas. Nova Odessa: Instituto Plantarum, 2003. 385 p.

PAIVA, H. N.; GOMES, J. M. Propagação Vegetativa de Espécies Florestais. Universidade Federal de Viçosa, Viçosa, 1995. 40 p.

PINHEIRO, A. L.; LANI, J. L.; COUTO, L. Cedro australiano: cultivo e utilização. Viçosa: Universidade Federal de Viçosa, 2006, 42 p.

PINHEIRO, A. L.; LANI, J. L.; COUTO, L. Cultura do Cedro Australiano para Produção de Madeira Serrada. Universidade Federal de Viçosa,
Viçosa, 2003. 42 p.

RYLTER, R. M. Fine root production and carbon and nitrogen allocation in basket willows. Uppsala. Thesis Doctoral. Swedish University of Agricultural Sciences. 1997.

SILVEIRA, R. L. V. de A. et al. Seja doutor do seu eucalipto. Arquivo do Agrônomo, n.12, p. 29. 2001.

SOUZA JUNIOR, L. de Tipo de minijardim clonal e efeito do ácido indolbutírico na miniestaquia de Grevillea robusta A. cunn. (proteaceae). 2007.66 f. Dissertação (Mestrado em Botânica). Universidade Federal do Paraná, Curitiba-PR, 2007.

SOUZA, J. C. A. V. de. et al. Propagação Vegetativa de Cedro Australiano (Toona ciliata M. Roemer) por Miniestaquia Revista Árvore, Viçosa, v.33, n.2, p.205-213, 2009.

TITON, M. et al. Eficiência das minicepas e microcepas na produção de propágulos de clones de Eucalyptus grandis. Revista Árvore, Viçosa, v.27, n.5, p.619-625, 2003.

WENDLING, I. et al. Influência da miniestaquia seriada no vigor de minicepas de clones de Eucalyptus grandis. Revista Árvore, Viçosa, v.27, n.5, p. 611-618, 2003.

WENDLING, I. F. Produção e sobrevivência de miniestacas e minicepas de erva-mate cultivadas em sistema semi-hidropônico. Pesquisa Agropecuária Brasileira, Brasília, v. 42, n. 2, p. 289-292, 2007.

XAVIER, A. et al. Propagação vegetativa de cedro rosa por miniestaquia. Revista Árvore, Viçosa, v. 27, n. 2, p.139-143, 2003.

ZANNI FILHO, J. Fundamentos para a estruturação de um viveiro. In. Produção de mudas em espécies florestais exóticas e nativas. Piracicaba: IPEF, p.12, 1997. 